\title{
THE ESMARCH BANDAGE AND PULMONARY EMBOLISM
}

\author{
M. Austin, London, England
}

The Esmarch bandage, a flat broad indiarubber bandage commonly used to exsanguinate limbs before operations needing a bloodless field, was described by von Esmarch, a German surgeon, in 1873 .

The risk of nerve palsy and arterial spasm with these bandages is well known, but the more serious risk of pulmonary embolism may not be commonly appreciated. I have recently been associated with two cases, both of which had a fatal outcome.

\section{CASE REPORTS}

Case 1-A heavy woman of fifty-two slipped and sustained a fracture-dislocation of the right ankle. Reduction was performed under a general anaesthetic and a split below-knee plaster was applied. She was kept in bed with the leg elevated, but further radiographs showed displacement of the fragments and it was decided that internal fixation of the medial malleolus was required. The operation was performed seven days after the injury. Induction of anaesthesia was normal, and the Esmarch bandage was applied to exsanguinate the leg. When the bandage had reached mid-thigh the patient suddenly became apnoeic and cyanosed. It was thought that laryngeal spasm was responsible, and after oxygenation her condition did not cause further concern until the operation had been completed, when the patient failed to recover consciousness. The pupils were dilated and fixed and remained so until death eleven hours later.

At post-mortem examination a massive pulmonary embolus, seven inches long, was found blocking both branches of the pulmonary artery, with paradoxical emboli in both internal carotid and middle cerebral vessels, due to a patent foramen ovale. Both the superficial and the deep veins of the calf of the fractured leg were filled with ante-mortem clot.

Case 2-An obese woman of forty-two fell and sustained a spiral fracture of the lowest third of the left tibia and fibula. The fracture was reduced under an anaesthetic and a split aboveknee plaster was applied. Thereafter she was kept in bed with the leg elevated, but radiographs showed that the position had not been maintained and it was decided that internal fixation was required. Operation was performed nine days after the injury. Induction of anaesthesia was uneventful, and the leg was exsanguinated in the usual way with an Esmarch bandage. Half way through the operation the pulse became irregular and cyanosis developed. While the plaster was being applied at the conclusion of the operation, after removal of the tourniquet, the heart stopped. Cardiac massage was performed without success.

Post-mortem examination showed a massive embolus filling both sides of the pulmonary artery. Extensive ante-mortem thrombi were found in the veins of the injured leg.

\section{COMMENT}

Both cases presented a similar sequence of events. A lower limb fracture had been reduced, the limb immobilised in plaster and the patient confined to bed for seven or nine days before operative intervention. In each case an Esmarch bandage was used to exsanguinate the limb, and the procedure was followed by a massive fatal pulmonary embolism. 
Before operation no clinical evidence of deep vein thrombosis had been noted, but the danger of silent thrombi in limbs immobilised in plaster has long been known. I do not think that the danger of using an exsanguinating bandage in the presence of such silent thrombi is adequately appreciated. Although it is possible that the embolism might have occurred spontaneously, the circumstances point decidedly to the exsanguinating bandage as the precipitating factor. A similar sequence of fracture, immobilisation and delayed internal fixation is common in orthopaedic practice, especially now that the advantages of delay in operation are becoming known. I suggest that the outcome of these two cases be borne in mind in such operations for lower limb fractures, and that a tourniquet should not be used routinely without consideration of the risk involved.

I am grateful to Mr G. T. F. Braddock and Mr D. R. Sweetnam for permission to publish these cases and for their help and encouragement.

\section{REFERENCE}

Esmarch, J. F. A. von (1873): Ueber künstliche Blutleere bei Operationen. Sammlung Klinischer Vorträge in Verbindung mit Deutschen Klinikern. Chirurgie 19, No. 58, p. 373. 